PHYSICAL REVIEW D 93, 089908(E) (2016)

\title{
Publisher's Note: Role of momentum and velocity for radiating electrons
} [Phys. Rev. D 93, 045034 (2016)]

\author{
Rémi Capdessus, Adam Noble, Paul McKenna, and Dino A. Jaroszynski
}

(Received 15 April 2016; published 22 April 2016)

DOI: 10.1103/PhysRevD.93.089908

This paper was published online on 26 February 2016 with an error in Eq. (1). Equation (1) should read as $\ddot{x}^{a}=\frac{e}{m}\left(F_{b}^{a}+\tau \dot{x}^{c} \partial_{c} F_{b}^{a}\right) \dot{x}^{b}+\tau \frac{e^{2}}{m^{2}} \Delta^{a}{ }_{b} F^{b}{ }_{c} F^{c}{ }_{d} \dot{x}^{d}$. The equation has been corrected as of 15 April 2016 . The equation is incorrect in the printed version of the journal. 